\title{
452125 - DOES A LOW VOLUME ULTRASOUND-GUIDED TECHNIQUE REDUCE COMMON COMPLICATIONS OF INTERSCALENE BRACHIAL PLEXUS BLOCK (ISBPB)?
}

\author{
Sheila Riazi, MSc, MD , Imad Awad, MD², Nicole Carmichael, PhD $^{2}$, Richard \\ Holtby, $\mathrm{MD}^{3}$, Colin McCartney, $\mathrm{MD}^{2}$ \\ 1. Anesthesia, University of Toronto, Toronto, ON, Canada \\ 2. Anesthesia, Sunnybrook Health Science Center, Toronto, ON, Canada \\ 3. Orthopedic Surgery, Sunnybrook Health Science Center, Toronto, ON, Canada
}

Introduction: ISBPB is one of the most effective and reliable nerve blocks for shoulder surgery(1). However, a one hundred percent incidence of phrenic nerve palsy(2) limits its useful application in patients with limited pulmonary reserve. In this study we examined the incidence of phrenic nerve palsy and diaphragmatic function with an ultrasoundguided low volume (5ml) ISBPB compared to a standard technique.

Methods: In this double-blind, randomized controlled trial after REB approval and informed consent forty patients, undergoing right-sided shoulder surgery, were enrolled, and randomized into two groups, receiving an ultrasound-guided posterior approach ISBPB of either $5 \mathrm{ml}$ or $20 \mathrm{ml}$ ropivacaine $0.5 \%$. General anesthesia was standardized. Both groups were assessed for respiratory function by visualizing diaphragmatic movement sonographically, and by measuring lung volumes using spirometry before and after receiving ISBPB, and also after surgery. As part of the respiratory function assessment, change in room air Oxygen saturation was also measured. The primary outcome was diaphragmatic function 30 minutes following ISBPB insertion. Pain scores at 12, and 24 hours, sleep quality, and total morphine equivalent consumption were additional secondary outcomes. Statistical comparison of continuous variables was analyzed using ANOVA and students t-test. Non-continuous variables were analyzed using chi-squared test. Significance is considered as p values lower than 0.05.

Results: The incidence of diaphragmatic paralysis was significantly lower in the lowvolume group at 30 minutes after the block (45\% vs. 100\%, $\mathrm{p}=0.001)$, and 60 minutes after the surgery (33\% vs. $90 \%, \mathrm{p}=0.001)$. Reduction in FEV1 ( -0.60 vs. $-1.23, \mathrm{p}=0.001)$, FVC (-0.70 vs. $-1.59, \mathrm{p}=0.001)$, and PEF ( -0.83 vs. $-2.50, \mathrm{p}=0.001)$ at 30 minutes after the block were also significantly less in the low-volume group. In addition, there was a significantly greater drop in Oxygen saturation in the standard-volume group (-5.85 vs. $1.50, \mathrm{p}=0.004$ ). Pain scores in low, and high-volume groups measured at 12 (mean: 3.26 vs. 2.84, $\mathrm{p}=0.428$ ), and 24 hours (mean: 4.89 vs. 5.84, $\mathrm{p}=0.226$ ) after the block, as well as sleep quality, and total morphine consumption (mean: 13.95 vs. $13.89, \mathrm{p}=0.993$ ) were statistically similar. There were three cases of Horner's syndrome, and three cases of hoarseness that all occurred in standard volume group. Additionally, there was a case of persistent hiccups in a patient who received standard volume ISBPB that lasted 3 days. Discussion: Our results indicate that the use of low volume $(5 \mathrm{ml})$ of ropivacaine $0.5 \%$ for ISBPB, is associated with lower incidence of phrenic nerve palsy, better preservation of diaphragmatic function, and overall fewer complications with no change in postoperative analgesia compared to standard-volume. 
References: 1- Brull R, McCartney CJL, Sawyer R, von Schroeder HP. The indications, and applications of interscalene brachialplexus block for surgery about the shoulder. Acute pain 2004;6: 57-77. 2-Urmey WF, Talts KH, Sharrock NE. One hundred percent incidence of hemidiaphragmatic paresis associated with interscalene brachial plexus anesthesia as diagnosed by ultrasonography. Anesth Analg 1991; 72:498-503. 